\title{
Correlation between Peripheral Arterial Disease and Coronary Artery Disease in Bangladeshi Population- A Five Years Retrospective Study \\ SYED DAWOOD MD. TAIMUR ${ }^{1}$, MASHHUD ZIA CHOWDHURY ${ }^{1}$, MD. ENAMUL HAKIM ${ }^{2}$
}

${ }^{1}$ Department of Cardiology, Ibrahim Cardiac Hospital \& Research Institute, Dhaka, ${ }^{2}$ Department of Cardiac surgery,National Institute of Cardiovascular Diseases(NICVD), Dhaka

Address of Correspondence: Dr. Syed Dawood Md. Taimur, Assistant Professor \& Associate Consultant, Department of Cardiology, Ibrahim Cardiac Hospital \& Research Institute, Dhaka, Bangladesh, Email: sdmtaimur@gmail.com

\begin{abstract}
:
Background: Peripheral arterial disease (PAD) is under diagnosed in primary care practices, yet the extent of unrecognized $P A D$ in patients with coronary artery disease (CAD) is unknown.

Objective: To assess the prevalence of previously unrecognized PAD in patients undergoing coronary angiogram and to determine the relationship between presence of $P A D$ and severity of CAD.
\end{abstract}

Material \& Methods: This five years retrospective study was conducted at invasive lab of the department of Cardiology, Ibrahim Cardiac Hospital \& Research Institute, Dhaka, Bangladesh from January 2010 to December 2014. Total 77 patients were included in this study. Study variables were age, sex, risk factors like hypertension, diabetes mellitus, dyslipidaemia, smoking habit and positive family history for ischemic heart disease, severity of coronary artery and peripheral artery disease.

Results: Mean age was $56.83 \pm 13.64$ years, Male mean age was $53.98 \pm 15.08$ years and female mean age was $54.5 \pm 1.73 y e a r s$. Hypertension were detected in $55.8 \%$, diabetes in $87 \%$, dyslipidaemia in $81.8 \%$, smoking habits in $88.3 \%$ and $58.4 \%$ had positive family history. After catheterization $88.3 \%$ had peripheral arterial disease and $71.4 \%$ had coronary artery disease. Out of 77 patients 52 had both coronary and peripheral arterial disease which was statistically significant (p<.014). Coronary angiogram revealed $28.6 \%(22)$ patients had triple vessel disease, $23.3 \%$ (18) had single vessel disease, 19.5\% (15) had double vessel disease and 28.6\% (22) were normal coronary arteries. Peripheral angiogram revealed $51.9 \%$ had superficial femoral artery disease, 24.7\% had anterior tibial artery disease, 26\% had posterior tibial artery disease, $15.6 \%$ had common iliac artery and common femoral artery disease and $2.6 \%$ had renal artery disease.

Conclusion: There is a strong and definite correlation between coronary and peripheral arterial disease. We found that cardiovascular risk factors were in fact risk factors for both PAD and CAD.

Keywords: Peripheral artery disease; Coronary artery disease; Risk factors.

Introduction:

Peripheral Artery Disease (PAD) is a distinct atherosclerotic syndrome marked by stenosis or occlusion of the arteries, particularly of the lower extremities. PAD affects 8 to 10 million individuals in the United States ${ }^{1,2}$ and is associated with reduced functional capacity ${ }^{3,4}$ and increased risk for cardiovascular morbidity and mortality ${ }^{5-}$ 7. Despite its widespread prevalence and negative associations with quality of life, morbidity, and mortality, PAD remains under diagnosed and undertreated $2,8,9$. Preventable or treatable risk factors for PAD are generally thought to mirror other forms of cardiovascular disease and include cigarette smoking, type 2 diabetes, and clinically elevated levels of blood pressure and cholesterol, which are the main therapeutic targets in clinical and prevention guidelines ${ }^{10,11}$. However, their respective associations with risk of PAD and the extent to which they are jointly associated with the incidence of PAD are not well established. Furthermore, despite the ongoing identification of novel risk factors for $\mathrm{PAD}^{12,13}$ this disease may have a less prominent component of thrombosis than does ischemic stroke or myocardial infarction (MI) ${ }^{14,15}$ ,raising the possibility that traditional atherosclerotic risk factors may be even more important in this form of cardiovascular disease.

Therefore, our objective in the present study was to analyze and compare risk factors for PAD, CAD, and for normal 
controls under the hypothesis that risk factors for PAD and $\mathrm{CAD}$ are different from those for normal controls.

\section{Subjects and Methods}

\section{Study population and design}

We reviewed the records of patients diagnosed with PAD and CAD at the department of Cardiology, Ibrahim Cardiac Hospital \& Research Institute from January2010 to December, 2014 who underwent duplex study of lower limb vessels with history of stable or unstable angina with risk factors like hypertension (HTN), diabetes mellitus (DM), dyslipidaemia, smoking habit, positive family history and history of CKD. We excluded patients who suffering multi-organ failure or cancer. The enrolled subjects consisted of 1) patients with clinical history of intermittent claudication of lower limb or limb ischemia who had over $50 \%$ peripheral artery occlusion confirmed by duplex study of lower limb vessels, 2) patients those with previous ischemic heart disease with or without risk factor .

\section{Diagnostic criteria}

\section{Cardiovascular risk factors}

Subjects were defined as having hypertension if they were taking an anti-hypertensive agent, had been clinically diagnosed with hypertension (HTN), or had either a systolic blood pressure (SBP) e $140 \mathrm{~mm} \mathrm{Hg}$ or a diastolic blood pressure (DBP) e $\bullet 90 \mathrm{~mm} \mathrm{Hg}$. Subjects who met one of the following requirements were defined as having diabetes mellitus(DM): on an oral hyperglycemic agent, using insulin, clinical diagnosis of diabetes, or a fasting glucose level $>126 \mathrm{mg} / \mathrm{dl}$ and 2 hours after blood sugar $>\mathrm{mg} / \mathrm{dl}$. Subjects were defined to have dyslipidaemia if they met one of the following requirements: diagnosis of hypercholesterolemia or a medication history of hypercholesterolemia or TChol $>200$ $\mathrm{mg} / \mathrm{dL}$ or LDL-C $>130 \mathrm{mg} / \mathrm{dL}$. The following body mass index (BMI) categories were recognized: normal $(18.5 \mathrm{~d} \bullet \mathrm{BMI}<24.9)$, overweight $(25 \mathrm{~d} \bullet \mathrm{BMI}<30)$ and obese (BMIe•30). A patient who had smoked within a year prior to the study was defined as a smoker. The estimated Glomerular Filtration Rate (eGFR), which was used as an indicator of kidney function, was calculated using the Modification of Diet Renal Disease Study formula: eGFR $(\mathrm{mL} / \mathrm{min} / 1.73 \mathrm{~m} 2)$. The National Kidney Foundation Kidney Disease Outcome Quality Initiative defined CKD as an eGFR $<60 \mathrm{~mL} / \mathrm{min} / 1.73 \mathrm{~m} 2$.

Statistical analysis The age and gender differences and hypertension, diabetes, dyslipidaemia, smoking habit, family history of IHD,CKD, peripheral artery and coronary artery profile were statistically analyzed to find if they influenced in any way the incidence of SD. Data were entered in computer using SPSS for windows version 16.0 (SPSS Inc., Chicago, IL). Results were cross-tabulated to find out the relationships between the variables. Statistical analysis was performed using $\div^{2}$-square for test of association and Fisher's exact test as appropriate. A pvalue of less than 0.05 was considered significant in all statistical analysis.

\section{Results:}

Mean age was $56.83 \pm 13.64$ years, Male mean age was $53.98 \pm 15.08$ years and female mean age was $54.5 \pm 1.73$ years. There were four different age groups in this study. 16 patients were in 30-45 years of age group, 34 patients were in 46-60 years age group, 20 patients were in $61-75$ years age group \& 7 patients were in more than 76 years age group. $93.51 \%$ were male and $6.49 \%$ were female. Out of 77 patients 7 patients BMI was less than $18.5,48$ patients BMI range was 18.5-24.9, 19 subject had 25-29.9 and rest 3 patients had more than 30 .Out of 68 patients who had PVD, 45 patients and Out of 55 patients who had CAD, 35 patients BMI was same range 18.5-24.9 and only 1 patient who suffered both PVD \& CAD his BMI was $>30$. (Fig.1)

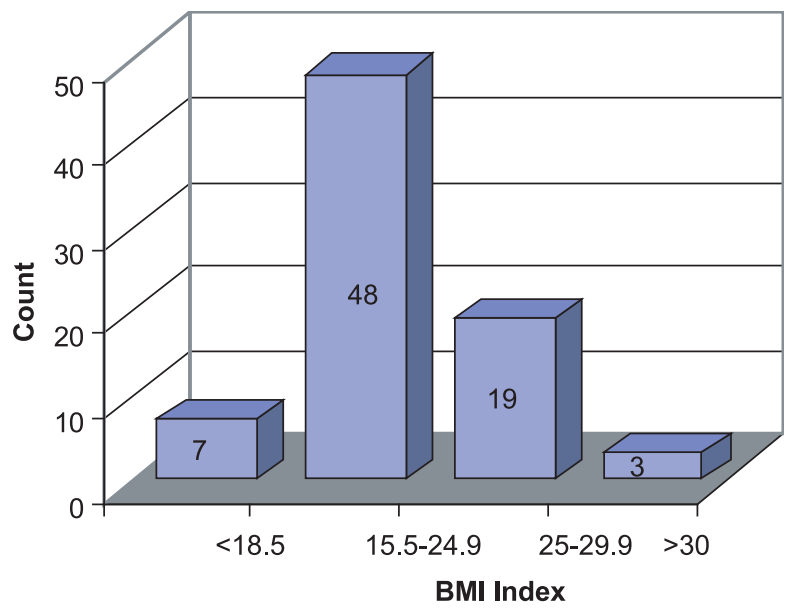

Fig.-1: Bar chart showed population in different range of $B M I$

Hypertension were detected in $55.8 \%$, diabetes in $87 \%$, dyslipidaemia in $81.8 \%$, smoking habits in $79.2 \%$ and $58.4 \%$ had positive family history who had PAD. On the other hand Hypertension were detected in $78.18 \%$, diabetes in $94.5 \%$, dyslipidaemia in $87.2 \%$, smoking habits in $80 \%$ and $14.5 \%$ had positive family history who had CAD.(Table-1) 
Table-I

Epidemiological characteristics difference between coronary and peripheral artery disease.

\begin{tabular}{lcccc}
\hline Characteristic & CAD & p-value & PAD & p-value \\
\hline HTN & 55 & .079 & 68 & .031 \\
DM & 55 & .005 & 68 & .003 \\
Dyslipidaemia & 55 & .055 & 68 & .052 \\
Smoking Habit & 55 & .507 & 68 & .035 \\
Family History for IHD & 55 & .000 & 68 & .024 \\
H/O CKD & 55 & .615 & 68 & .621 \\
\hline
\end{tabular}

After catheterization $88.3 \%$ had peripheral arterial disease and $71.4 \%$ had coronary artery disease. Out of 77 patients 52 had both coronary and peripheral arterial disease which was statistically significant $(\mathrm{p}<.014)$. Coronary angiogram revealed $28.6 \%$ (22) patients had triple vessel disease, $23.3 \%$ (18) had single vessel disease, $19.5 \%(15)$ had double vessel disease and $28.6 \%$ (22) were normal coronary arteries. (Table-2)

\section{Table-II}

Difference between male and female number of coronary artery disease and Individual coronary artery lesion.

\begin{tabular}{lcccc}
\hline Sex & SVD & DVD & TVD & Normal \\
\hline Male & 15 & 14 & 22 & 21 \\
Female & 3 & 1 & 0 & 1 \\
Total(77) & 18 & 15 & 22 & 22 \\
\hline Name of Coronary artery & Frequency & Percentage (\%) \\
\hline Left main & 1 & 1.3 \\
LAD & 43 & 55.8 \\
LCx & 36 & 46.8 \\
RCA & 34 & 44.2 \\
\hline
\end{tabular}

After coronary angiogram $33.8 \%$ patient advised PCI, $23.4 \%$ advised CABG, $14.3 \%$ had optimized medical management and $28.6 \%$ recommendation was primary prevention.(Fig.2)

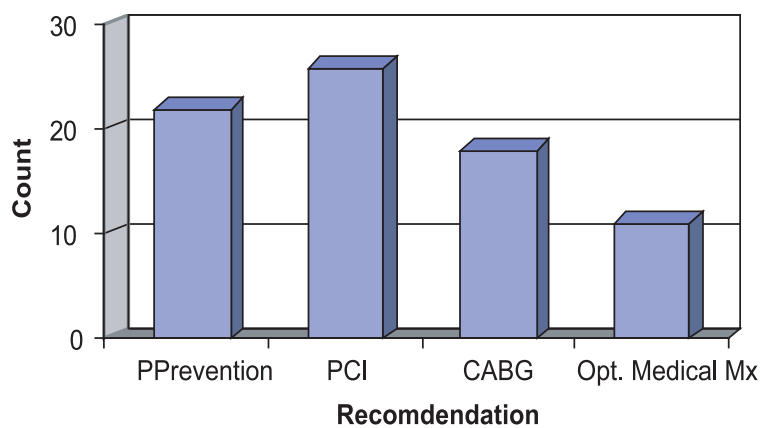

Fig.-2: Bar chart showed Recommendation after coronary artery disease
Peripheral angiogram revealed $51.9 \%$ had superficial femoral artery disease, $24.7 \%$ had anterior tibial artery disease, $26 \%$ had posterior tibial artery disease, $15.6 \%$ had common iliac artery and common femoral artery disease and $2.6 \%$ had renal artery disease.

\section{Table-III}

Frequency and percentage of Peripheral artery disease

\begin{tabular}{lcc}
\hline Name of Peripheral Artery & Frequency & Percentage $(\%)$ \\
\hline Renal & 2 & 2.6 \\
Superficial Femoral & 40 & 51.9 \\
Post.Tibial & 20 & 26 \\
Anterior Tibial & 19 & 24.7 \\
External Iliac & 8 & 10.4 \\
Common Femoral & 12 & 15.6 \\
Aorto-iliac or Femoral & 10 & 13 \\
Common Iliac & 12 & 15.6 \\
\hline
\end{tabular}

Recommendation after peripheral angiogram revealed $48.1 \%$ patients advised bypass graft surgery, 35.1\% advised peripheral angioplasty (PTA), 5.2\% medical management and $11.7 \%$ recommended primary prevention.

\section{Discussion:}

Peripheral arterial disease is the occlusive disease of arteries distal to the aortic bifurcation ${ }^{16}$. The term, however, is widely used to refer to chronic arterial disease of the legs of atherosclerotic origin. Atherosclerosis is by far the most common cause ( $>90 \%$ ) of arterial problems in the legs ${ }^{17}$.

The overall findings of this study revealed that hypertension, diabetes, dyslipidaemia, obesity, smoking habit and CKD are risk factors for peripheral artery and coronary artery disease. However, obesity as a risk factor showed inconsistent results between PAD and CAD. These findings are consistent with those of previous studies that reported that risk factors for PAD are similar to those for CAD. For instance, $\mathrm{HTN}^{20}, \mathrm{DM}^{21}$, dyslipidaemia ${ }^{22}$, smoking ${ }^{23}$, and $\mathrm{CKD}^{24}$, are known risk factors for CAD. Furthermore, $\mathrm{HTN}^{25}, \mathrm{DM}^{26}$, dyslipidaemia ${ }^{27}$, smoking ${ }^{28}$, and $\mathrm{CKD}^{19}$, are risk factors for PAD. Obesity is one of the major risk factor for CVD, including PAD.21) Obesity is also associated with high mortality related to chronic disease ${ }^{32}$. However, patients with CAD or PAD have an inverse correlation between BMI and cardiovascular mortality after adjustment for confounding variables in the Factores de Riesgo y ENfermedad Arterial registry ${ }^{33}$.

This study population when analyzed age wise, the prevalence in age group of $30-45$ years was $20.8 \%$. It 
increased to $44.2 \%$ in $46-60$ years age group, $26 \%$ in the age group $61-75$ years and $9.1 \%$ in more than 76 years age group. Peripheral arterial disease occurrence increased with age. Most studies have shown a linear relation between age and PAD. The Rotterdam Study showed a prevalence of $7.6 \%$ in age group of 55-59 years, which increased to $59.6 \%$ in age $>85$ years $^{35}$. Newman et al. have shown a prevalence of $26 \%$ in a population aged e" 60 years ${ }^{34}$. This is comparable to the present study which has a prevalence of PAD of $44.2 \%$ of the patients in the study population 46-60 years of age. In this study population, the male subjects comprised $93.5 \%$ and female subjects comprised $6.5 \%$. The occurrence of PAD among males was $92.6 \%$ and females was $7.4 \%$ PAD . The impact of sex on PAD, however, did not reach statistical insignificance in this study. Most of the studies have shown a similar incidence of PAD with men to be slightly more than women. Schroll and Munk have shown an incidence of $16 \%$ in men and $13 \%$ in women ${ }^{16}$. The Cardiovascular Health Study has shown a prevalence of $14 \%$ for men and $11 \%$ for women ${ }^{34}$.Vogt et al. have shown the gap in prevalence narrows after 70 years of age ${ }^{40}$. However, Meijer et al. in the Rotterdam Study found a higher prevalence rate among women being at $20.5 \%$ and for men being at $16.9 \%{ }^{35}$.. Another interesting fact observed was the presence of claudication seen more among subjects who also had associated CAD. Reunanen et al. had also made a similar observation in their study ${ }^{36}$. In this study, among the patients diagnosed to having PAD, $21 \%$.

This study showed that $87 \%$ of patients with DM had PAD and the $P$ value for DM as a risk factor was statistically significant. A cross-sectional study by Adler et al. found a prevalence of $23.5 \%$ PAD among type $2 \mathrm{DM}$ patients ${ }^{37}$. In the study by Beckman et al., $50 \%$ of patients with $\mathrm{DM}$ were found to have $\mathrm{PAD}^{38}$. In our study, the occurrence of PAD in diabetics 46-60 years of age went up to $47 \%$. However, regardless of high prevalence and complication that can result from PAD, it is still not a common practice to routinely screen for the disease in diabetics.

In our study, 96.1\% were smokers and most of them were males. Occurrence of PAD among smokers was around 98.5\% which was significantly higher than among nonsmokers (1.5\%). 91.89\% of the PAD-positive cases were smokers. Smoking as a risk factor had a statistically significant $P$ value (0.035). Studies like Framingham Study, Cardiovascular Health Study, and Edinburgh Artery Study showed that amongst smokers PAD was 2-5 times higher ${ }^{34,39}$. Willingdael et al. have shown that PAD is 2.5 times more in smokers ${ }^{41}$. In our study, PAD was higher in smokers than in nonsmokers with a significant $P$ value.

The present study had $55.8 \%$ of subjects as hypertensive; $\%$ had PAD whereas a similar proportion of $39.7 \%$ among non-hypertensive had PAD. The $P$ value was statistically significant ( $P$ value 0.035$)$. According to the Framingham Heart Study, hypertension doubles the risk of PAD ${ }^{39}$. However, Reunanen et al. showed that hypertension was not significantly related to $\mathrm{PAD}^{36}$. In our study occurrence of PAD in both groups was similar. The present study population of 77 patients had 35 patients (45.45\%) who had CAD. However, the occurrence of CAD among patients who had PAD was 2 times more than those without PAD. Among PAD-positive cases, CAD was present in 94.5\%. Only $5.5 \%$ of PAD-negative cases had CAD.

A strong correlation was found to occur between PAD and CAD ( $P=0.014$; statistically significant $)$. The PARTNERS program showed that $16 \%$ of patients had PAD and CAD, 13\% had only PAD, and $24 \%$ had only CAD. 12 In our study $94.5 \%$ had PAD and CAD, $23.5 \%$ had only PAD, and $5.45 \%$ had only CAD.

\section{Conclusions:}

There is a definite and strong correlation between PAD and CAD. In view of the increasingly aging population and associated increase in atherosclerotic vascular disease, confrontation with patients of PAD will increase, which however, continues to be under diagnosed and under treated. Correct diagnosis and supervision of patients with these disorders is important for the prevention of local progression of the disease and effective secondary prevention of any future coronary and cerebrovascular events.

\section{References:}

1. Allison MA, Ho E, Denenberg JO, et al. Ethnicspecific prevalence of peripheral arterial disease in the United States. Am J Prev Med. 2007;32(4):328-33.

2. Pande RL, Perlstein TS, Beckman JA, Creager MA.Secondary prevention and mortality in peripheral artery disease: National Health and Nutrition Examination Study, 1999 to 2004. Circulation. 2011;124(1):17-23.

3. McDermott MM, Liu K, Greenland P, et al. Functional decline in peripheral arterial disease: associations with the ankle brachial index and leg symptoms. JAMA. 2004;292(4): 453-461.

4. McDermott MM, Guralnik JM, Tian L, et al. Associations of borderline and low normal ankle-brachial index values with functional decline at 5-year followup: the WALCS (Walking and Leg Circulation Study). J Am Coll Cardiol. 2009;53(12):1056-62. 
5. Fowkes FG, Murray GD, Butcher I, et al; Ankle Brachial Index Collaboration. Ankle brachial index combined with Framingham risk score to predict cardiovascular events and mortality: ameta-analysis. JAMA.2008;300(2):197-208.

6. Steg PG, Bhatt DL, Wilson PW, et al; REACH Registry Investigators. One-year cardiovascular event rates in outpatients with atherothrombosis. JAMA. 2007; 297(11):1197-1206.

7. Golomb BA, Dang TT, Criqui MH. Peripheral arterial disease: morbidity and mortality implications.Circulation. 2006;114(7):688-699.

8. Hirsch AT, Criqui MH, Treat-Jacobson D, et al. Peripheral arterial disease detection, awareness, and treatment in primary care. JAMA. 2001;286(11):1317-24.

9. Cacoub PP, Abola MT, Baumgartner I, et al; REACH Registry Investigators. Cardiovascular risk factor control and outcomes in peripheral artery disease patients in the Reduction of Atherothrombosis for Continued Health (REACH) Registry. Atherosclerosis. 2009;204(2):e86-e92.

10. Hirsch AT, Haskal ZJ, Hertzer NR, et al; American Association for Vascular Surgery; Society for Vascular Surgery; Society for Cardiovascular Angiography and Interventions; Society for Vascular Medicine and Biology; Society of Interventional Radiology; ACC/AHA Task Force on Practice Guidelines Writing Committee to Develop Guidelines for the Management of Patients With Peripheral Arterial Disease; American Association of Cardiovascular and Pulmonary Rehabilitation; National Heart, Lung, and Blood Institute; Society for Vascular Nursing; Trans Atlantic Inter-Society Consensus; Vascular Disease Foundation.ACC/AHA 2005 Practice Guidelines for the management of patients with peripheral arterial disease (lower extremity, renal, mesenteric, and abdominal aortic): a collaborative report from the American Association for Vascular Surgery/Society for Vascular Surgery, Society for Cardiovascular Angiography and Interventions, Society for Vascular Medicine and Biology, Society of Interventional Radiology, and the ACC/AHA Task Force on Practice Guidelines (Writing Committee to Develop Guidelines for the Management of Patients with Peripheral Arterial Disease): endorsed by the American Association of Cardiovascular and Pulmonary Rehabilitation; National Heart, Lung, and Blood Institute; Society for Vascular Nursing; TransAtlantic Inter-Society Consensus; and Vascular Disease Foundation. Circulation. 2006;113(11):e463-e654.

11. Norgren L, Hiatt WR, Dormandy JA, Nehler MR,Harris KA, Fowkes FGR; TASC II Working Group. Inter- Society Consensus for the Management of Peripheral Arterial Disease (TASC II). J Vasc Surg. 2007; 45(1)(suppl S):S5-S67.

12. Ho DY, Cook NR, Britton KA, et al. High-molecularweight and total adiponectin levels and incident symptomatic peripheral artery disease in women: a prospective investigation. Circulation. 2011;124(21): 2303-11.

13. Perlstein TS, Pande RL, Beckman JA, Creager MA. Serum total bilirubin level and prevalent lowerextremity peripheral arterial disease: National Health and Nutrition Examination
Survey (NHANES) 1999 to 2004. Arterioscler Thromb Vasc Biol. 2008;28 (1):166-172.

14. Bonow RO, Mann DL, Zipes DP, Libby P. Braunwald'sHeart Disease: A Textbook of Cardiovascular Medicine. 9th ed. Philadelphia, PA: Saunders Elsevier; 2011:1338-58.

15. Dhaliwal G, Mukherjee D. Peripheral arterial disease: epidemiology, natural history, diagnosis and treatment. Int $J$ Angiol. 2007;16(2):36-44.

16. Lanzer P. Peripheral Vascular Disease-The Textbook of Peripheral Vascular Medicine (ed.). Eric J Topol 388-96.

17. Halperin JL. Evaluation of patients with peripheral vascular disease. Thromb Res 2002;106:303-11.

18. Gorter PM, Olijhoek JK, van der Graaf Y, Algra A, Rabelink TJ, Visseren FL; SMART Study Group. Prevalence of the metabolic syndrome in patients with coronary heart disease, cerebrovascular disease, peripheral arterial disease or abdominal aortic aneurysm. Atherosclerosis 2004;173:363-9.

19. Kon V, Linton MF, Fazio S. Atherosclerosis in chronic kidney disease: the role of macrophages. Nat Rev Nephrol 2011; 7:45-54.

20. Hozawa A, Okamura T, Murakami Y, et al. Joint impact of smoking and hypertension on cardiovascular disease and allcause mortality in Japan: NIPPON DATA80, a 19-year followup. Hypertens Res 2007;30:1169-75.

21. Eckel RH, Wassef M, Chait A, et al. Prevention Conference VI: Diabetes and Cardiovascular Disease: Writing Group II: pathogenesis of atherosclerosis in diabetes. Circulation 2002;105:e138-43.

22. Hatmi ZN, Mahdavi-Mazdeh M, Hashemi-Nazari SS, Hajighasemi E,Nozari B, Mahdavi A. Trend of lipid ratios associated with well known risk factors of coronary artery disease in different age: a population based study of 31,999 healthy individuals. Int $J$ Cardiol 2011;151:328-32.

23. Higashiyama A, Okamura T, Ono Y, Watanabe M, Kokubo Y, Okayama A. Risk of smoking and metabolic syndrome for incidence of cardiovascular disease-comparison of relative contribution in urban Japanese population: the Suita study. Circ J 2009;73:2258-63.

24. Kokubo Y, Nakamura S, Okamura T, et al. Relationship between blood pressure category and incidence of stroke and myocardial infarction in an urban Japanese population with and without chronic kidney disease: the Suita Study. Stroke 2009;40:2674-9.

25. Bennett PC, Silverman S, Gill P. Hypertension and peripheral arterial disease. J Hum Hypertens 2009;23:213-5.

26. American Diabetes Association. Peripheral arterial disease in people with diabetes. Diabetes Care 2003; 26:3333-41.

27. Pasternak RC, Criqui MH, Benjamin EJ, et al. Atherosclerotic Vascular Disease Conference: Writing Group I: epidemiology. Circulation 2004;109: 2605-12.

28. Willigendael EM, Teijink JA, Bartelink ML, et al. Influence of smoking on incidence and prevalence of peripheral arterial disease. J Vasc Surg 2004;40:1158-65. 
29. Tamura U, Tanaka T, Okamura T, et al. Changes in Weight, cardiovascular risk factors and estimated risk of coronary heart disease following smoking cessation in Japanese male workers: HIPOP-OHP study. J Atheroscler Thromb 2010;17: $12-20$.

30. Hwang YC, Jee JH, Oh EY, et al. Metabolic syndrome as a predictor of cardiovascular diseases and type 2 diabetes in Koreans. Int J Cardiol 2009; 134:313-21.

31. Carroll MD, Lacher DA, Sorlie PD, et al. Trends in serum lipids and lipoproteins of adults, 1960-2002. JAMA 2005;294 :1773-81.

32. Bogers RP, Bemelmans WJ, Hoogenveen RT, et al. Association of overweight with increased risk of coronary heart disease partly independent of blood pressure and cholesterol levels: a meta-analysis of 21 cohort studies including more than 300 000 persons. Arch Intern Med 2007; 167:1720-8.

33. Barba R, Bisbe J, Pedrajas JN, et al. Body mass index and outcome in patients with coronary, cerebrovascular, or peripheral artery disease: findings from the FRENA registry. Eur J Cardiovasc Prev Rehabil 2009; 16:457-63.

34. Newman AB, Siscovick BS, Manolio TA. Ankle arm index as a marker of atherosclerosis - the Cardiovascular Health Study. Circulation 1993;88:837-45.
35. Meijer WT, Hoes AW, Dominique R, Bots ML, Hofman A, Grobbee DE. Peripheral arterial disease in the elderly - the Rotterdam Study. Arterioscler Thromb Vasc Biol 1998; 18:185-92.

36. Reunanen A, Takkunen H, Aromaa A. Prevalence of intermittent claudication and its effect on mortality. Acta Med Scand 1982; 211:249-56.

37. Adler AL, Stevens RJ, Neil A, Stratton IM, Boulton AJ, Holman RR. UKPDS 59 - hyperglycemia and other potentially modifiable risk factors for peripheral vascular disease in type 2 diabetes. Diabetes Care 2002;25:894-9.

38. Beckman JA, Creager MA, Libby P. Diabetes in atherosclerosis - epidemiology, pathophysiology and management. JAMA 2002; 287:2570-81.

39. McKee PA, Castelli WP, McNamara PM, Kannel WB. The natural history of congestive heart failure - the Framingham Study. N Eng1 J Med 1971;285:1441-6.

40. Vogt MT, Wolfson SK, Kuller LH. Lower extremity arterial diseaseand the aging process - review. J Clin Epidemiol 1992;45:529-42.

41. Willingdael EM, Teijink JA, Bartelink ML, et al. Influence of smoking on incidence and prevalence of peripheral arterial disease. J Vasc Surg 2004;40:1158-65. 